\section{Research Square \\ Preprints are preliminary reports that have not undergone peer review. \\ They should not be considered conclusive, used to inform clinical practice, or referenced by the media as validated information.}

\title{
Research on Gradient Additive Remanufacturing of Ultra-large Hot Forging Die Based on Automatic Wire Arc Additive Manufacturing Technology
}

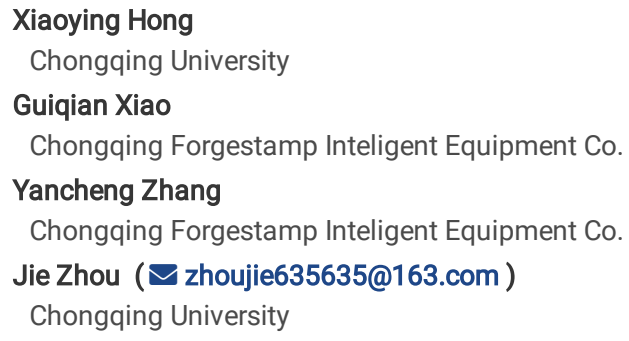

\section{Research Article}

Keywords: gradient additive manufacturing, ultra-large hot forging die, layering design, automatic WAAM technology

Posted Date: February 12th, 2021

DOI: https://doi.org/10.21203/rs.3.rs-212116/v1

License: () (1) This work is licensed under a Creative Commons Attribution 4.0 International License. Read Full License

Version of Record: A version of this preprint was published at The International Journal of Advanced Manufacturing Technology on July 7th, 2021. See the published version at https://doi.org/10.1007/s00170-021-07424-5. 


\section{Abstract}

In this paper, an automatic WAAM technology are proposed to realize the gradient additive remanufacturing of ultra-large hot forging dies. Firstly, a vertical additive manufacturing strategy and a normal additive manufacturing strategy are proposed to meet different additive manufacturing demands. Secondly, the basic principle of layering design of ultra-large hot forging dies is developed, and the wear resistance of Ni-based, Co-based and Fe-based alloys at room temperature and high temperature is analyzed. The Co-based alloy has the best high temperature wear resistance, which can be used on the surface of the hot forging die to strengthen the die. In order to control the forming quality of additive manufacturing, the relationship between welding parameters and weld shape was discussed, and the reverse system of welding process parameters was built. Finally, a typical aviation ultra-large hot forging die is selected as the research object. According to different stress and temperature distribution in different regions of the ultra-large hot forging die in service, materials with different properties are used in corresponding regions to improve the service life of the die, reduce the remanufacturing costs and improve the remanufacturing efficiency. The experimental results show that the service life of the hot forging die repaired by the automatic gradient function WAAM technology is significantly increased, the material is reduced by more than $50 \%$ and the production efficiency is increased by more than $50 \%$.

\section{Introduction}

The service life of a ultra-large hot forging die is extremely low due to the severe service conditions with high-temperature and heavy-load. In addition, the manufacturing of a new die needs complex processes such as casting, machining, heat treatment. Therefore, the cost of a ultra-large hot forging die is very high $^{[1][2][3]}$.

Thanks to the advantages of the wire arc additive manufacturing(WAAM) technology, high precision, high efficiency, low cost, less pollution ${ }^{[4][5]}$ and so on, the remanufacturing of ultra-large hot forging dies can be done at lower costs ${ }^{[6]}$. However, there are still many problems in the industrial application of WAAM technology such as pores, inclusions and weld shape control. Recently, WAAM technology has been widely studied ${ }^{[7]}$ to solve these problems. Ding et al ${ }^{[8][9]}$ developed a new path planning algorithm and a process control system, and their results show that the additive path is the key factor affecting welding quality. In order to solve the problem of non-uniform filling for complex sections, D Ding ${ }^{[10][11]}$ developed a control strategy of section filling based on artificial neural network prediction model, in which the weld width can be changed in real time. Similarly, Jin $Y^{[12]}$ also proposed an additive manufacturing path planning algorithm based on non-uniform filling, and trial produced several samples using this algorithm. Nguyen L $^{[13]}$ developed a multi-directional additive manufacturing path planning algorithm to overcome the limitation of unidirectional additive manufacturing. In which, the axis of each sub model is constructed, and then the slicing direction is constructed according to these axes. The complex components can be manufactured by additive manufacturing using this method. At present, the research on the path planning of WAAM technology is relatively complete, and gradually applied in the manufacture of parts. However, the research of applying the WAAM technology on the remanufacturing and performance improvement of forging die is relatively less. In addition, most of the researches focused on the additive manufacturing of one kind of material, and very few of them focused on the gradient additive manufacturing with multiple materials. One of the greatest advantages of WAAM technology is that different materials can be efficiently and controllably stacked in different regions. This advantage makes the WAAM technology potentially the most effective method to improve the service life and reduce the cost of ultra-large hot forging die. According to the service conditions and failure modes of a hot forging die, different areas of the die need different mechanical properties ${ }^{[14][15]}$. Lu $S^{[16]}$ proposed a method to repair forging dies with manual WAAM. The surface strength and hardness of the die are strengthened by covering high-strength material on the surface of die. However, there are many disadvantages of the manual remanufacturing of ultra-large hot forging die, such as low efficiency, bad working environment, low material utilization rate, difficult weld shape control.

To tackle these challenges, an automatic WAAM technology are proposed to realize the gradient additive remanufacturing of ultra-large hot forging dies in this paper. According to the different stress and temperature distributions in different regions of the ultra-large hot forging die in service, materials with different properties are added to corresponding regions to improve the service life of the die, reduces the remanufacturing costs and improves the remanufacturing efficiency. The automatic gradient additive remanufacturing is then conducted for a failed ultra-large forging die to verify the feasibility of the proposed innovative method.

\section{Additive Manufacturing Strategy}

According to different purposes of additive manufacturing, two path planning strategies are designed. The first strategy is called vertical additive manufacturing(VAM), which discretizes the target model into a series of sections in the vertical direction and fills these sections using plane filling algorithm. The second strategy, called normal additive manufacturing(NAM), offsets the target model to produce a series of space surfaces along the normal direction and fills them using surface filling algorithm. The first one is suitable for the manufacturing of parts or large-volume additive manufacturing as shown in Fig.1a. The second mode is suitable for surface additive manufacturing and is often used for surface coating additive manufacturing as shown in Fig.1b.

The first strategy cannot achieve the goal of distributing same material in the normal direction of the die surface, so the normal homogeneous gradient additive manufacturing cannot be achieved. In the second strategy, due to the normal offset of cavity surface, the same material can be uniformly covered on the die base, so the additive manufacturing with normal uniform thickness can be achieved.

\subsection{Vertical Additive Manufacturing(VAM)}


At presents, most of the additive manufacturing strategies used in 3D printing belong to the category of vertical additive manufacturing. This strategy greatly simplifies the difficulty of additive manufacturing by completely transforming 3D problem into 2D problem. The target model is discretized into a series of sections in the vertical direction as shown in Fig. $\mathbf{2 a}$, and then specific filling algorithms are used to fill these sections. In particular, the commonly used plane section filling algorithms are offset filling and linear filling as shown in Fig. 2b,c.

As shown in Fig. 2b, the filling quality of the offset filling algorithm is good in the boundary region, while the internal region has many filling defects such as over-filling or under-filling. In contrast, the linear filling algorithm has good internal filling quality and poor boundary filling quality as shown in Fig. $\mathbf{2 c}$. In order to overcome the disadvantages of these two algorithms, a hybrid filling algorithm is proposed in this paper, in which the boundary region is filled with offset filling algorithm, and the internal region is filled with linear filling algorithm.

\subsection{Normal Additive Manufacturing(NAM)}

It is difficult to obtain additive manufacturing layer with thin and uniform thickness by using VAM for some surface strengthening processes. Therefore, the normal additive manufacturing strategy is extremely important for this situation. For example, the surface of an ultra-large die cavity needs to be coated with a thin layer of strengthening material as shown in Fig. 3. The multi-layer shell model, the target model, is obtained by the normal offset algorithm of surface. The target model can be filled by space surface filling algorithm in which the space surface is slicing into many welding paths by a series of planes.

Thanks to the thickness of the solid target model is so small, the number of surface target model is also less. Therefore, it is convenient to transform the solid target model into a surface target model in normal direction. The plane used to slice the target surface model can be described by the equation of . In practice, different coefficients should be selected according to the characteristic of the target model. For example, the coefficients of the model from Fig.3c are set to: .The coefficients of the model from Fig.3d are set to: .

\section{Process Design Of Waam}

\subsection{Layer Design}

\subsubsection{Principle of Layer Design}

In hot forging process, the billet is usually heated to a higher temperature, so the surface temperature of the die is usually much higher than the inner temperature. In addition, humps and pits exist on the cavity surface, the stress and temperature distribution have extreme values in these regions. The cavity surface is in direct contact with the billet, and the friction is quite intense. For example, according to the simulation results of the temperature and the equivalent stress for a typical ultra-large hot forging die in service, the surface area of die cavity has the highest temperature, so the surface area is prone to have wear, burning, collapse, peeling as shown in Fig. 4.

Therefore, a better design is that the cavity surface has higher high-temperature wear resistance, the die transition layer also has higher strength, and the die base has better toughness ${ }^{[17]}$. As shown in Fig. $\mathbf{5}$, a failure hot forging die is redesigned into a three-layer structure, and the automatic WAAM technology is used to remanufacture the failure die. The thickness of the transition layer and the strengthening layer are determined according to the numerical simulation results of temperature distribution and stress distribution of the hot forging die in service.

When the hot forging die is in service, the surface temperature of the cavity is above 800 , and the strength of Fe-based alloy is very low at such a high temperature. Because the high temperature area is mostly concentrated on the surface of the die ${ }^{[18]}$, the thickness of the surface strengthening layer is very small, and only the NAM strategy can be used to achieve uniform additive manufacturing.

\subsubsection{Material Design}

According to the analysis in the previous section, the surface region of hot forging die needs high high-temperature wear resistance, which is usually found in Ni-based and Co-based alloy materials ${ }^{[19][20][21]}$. In order to ensure that the Ni-based alloy material can achieve the strengthening effect, the following alloy materials shown in Table 1 are designed, a high-temperature wear resistance experiment is designed to analyze the high-temperature performance of the material.

Table 1 Composition of welding wire materials in different layers(wt., \%)

\begin{tabular}{|lllllllllll|}
\hline Materials & $\mathrm{C}$ & $\mathrm{Si}$ & $\mathrm{Mn}$ & $\mathrm{Cr}$ & $\mathrm{Mo}$ & $\mathrm{W}$ & $\mathrm{V}$ & $\mathrm{Ni}$ & $\mathrm{Co}$ & $\mathrm{Fe}$ \\
Fe-based & 0.24 & 0.75 & 1.00 & 5.43 & 2.42 & 1.79 & 0.35 & - & - & Bal. \\
\hline Ni-based & 0.035 & 0.36 & 2.65 & 15.88 & 1.33 & - & - & Bal. & - & 7.75 \\
\hline Co-based & 0.22 & 1.00 & 1.03 & 27.51 & 2.76 & 0.13 & - & 2.36 & Bal. & 1.59 \\
\hline
\end{tabular}

To reduce the remanufacturing cost and improve the service life of the die, the transition layer is made of Fe-based alloy with low price, and the strengthening layer is made of Co-based or Ni-based alloy with high high-temperature wear resistance. The strengthening layer is usually designed to be very thin, about 8- 
$10 \mathrm{~mm}$, so the use of expensive Ni-based alloy materials has a little impact on the repair cost of die, while Co-based and Ni-based alloy materials can greatly increase the service life.

As shown in Fig.6, the ball-disc high-speed friction machine was used to study low-temperature and high-temperature wear resistance performance of the three materials. The specimen size used in the experiment was $50 \mathrm{~mm} \star 5 \mathrm{~mm}$, and the same surface polishing was carried out on each specimen, and them the specimens were cleaned with alcohol. As the billet temperature is usually higher than 800 , the specimens of the three materials were rubbed at 25,300 and 800 for $60 \mathrm{~min}$. In addition, due to the heavy-load borne by the hot forging die in service, the load applied in the experiment was about $200 \mathrm{~N}$.

Figure 7 compares the worn tack width and depth of Fe-based, Co-based and Ni-based alloys. Compared with other two kinds of materials, Ni-based alloy has the largest wear volume at temperature of $25^{\circ} \mathrm{C}$. The wear volume of Co-based alloy is similar to Fe-based alloy at temperature of $25^{\circ} \mathrm{C}$. The wear volume of Ni-based alloy decreases and the wear volume of Co-based alloy is slightly less than Fe-based alloy at temperatures of 300 . The wear volume of Co-based

alloy is significantly decreased when the experiment temperature is reached $800^{\circ} \mathrm{C}$. The wear resistance of Co-based and Ni-based alloy increases significantly with the increase of temperature, while that of Fe-based alloy is opposite.

\subsection{Welding Process Parameters}

To obtain higher geometric precision of hot forging die in the process of WAAM, this section discusses the relationship between welding process parameters and the geometry size of weld bead.

First the welding experiment of Fe-based alloy is carried out, and secondly a prediction model based on BP artificial neural network and inverse system based on genetic algorithm are established so that the welding parameters can be obtained quickly. The welding process of Ni-based alloy and Co-based alloy can be quickly obtained by the same method. The welding parameters that affect the shape of the weld bead mainly include: welding voltage, wire feeding speed and welding speed. If the welding voltage is too low, the weld bead will be high in height and narrow in width. If the welding voltage is too high, the welding heat will be large in the welding process, the weld bead with large width and low height will be formed. Therefore, $24 \mathrm{~V}-30 \mathrm{~V}$ is a more reasonable voltage range for welding wire with diameter of $1.3 \mathrm{~mm}$. The experimental welding voltage is set as: $24 \mathrm{~V}, 26 \mathrm{~V}, 28 \mathrm{~V}, 30 \mathrm{~V}$; Wire feeding speed is set as: $5000 \mathrm{~mm} / \mathrm{min}$, $7000 \mathrm{~mm} / \mathrm{min}, 9000 \mathrm{~mm} / \mathrm{min}, 11000 \mathrm{~mm} / \mathrm{min}$; The welding speed is set as: $500 \mathrm{~mm} / \mathrm{min}, 700 \mathrm{~mm} / \mathrm{min}, 900 \mathrm{~mm} / \mathrm{min}, 1100 \mathrm{~mm} / \mathrm{min}$. A total of 64 experiments were conducted, and the experimental data are shown in Table 2.

Table2 Weld shapes under different welding process parameters 


\begin{tabular}{|c|c|c|c|c|c|c|c|c|c|c|c|}
\hline number & $\begin{array}{l}\text { voltage } \\
\text { (V) }\end{array}$ & $\begin{array}{l}\text { Feeding } \\
\text { speed } \\
(\mathrm{mm} / \mathrm{min})\end{array}$ & $\begin{array}{l}\text { Welding } \\
\text { speed(mm/min) }\end{array}$ & width(mm) & height(mm) & number & $\begin{array}{l}\text { voltage } \\
\text { (V) }\end{array}$ & $\begin{array}{l}\text { Feeding } \\
\text { speed } \\
\text { (mm/min) }\end{array}$ & $\begin{array}{l}\text { Welding } \\
\text { speed(mm/min) }\end{array}$ & width(mm) & $\mathrm{h}$ \\
\hline 1 & 24 & 7000 & 500 & 5.52 & 3.57 & 33 & 28 & 7000 & 500 & 8.81 & 2 \\
\hline 2 & 24 & 7000 & 700 & 4.74 & 3.03 & 34 & 28 & 7000 & 700 & 7.03 & 1 \\
\hline 3 & 24 & 7000 & 900 & 3.65 & 2.59 & 35 & 28 & 7000 & 900 & 6.36 & 1 \\
\hline 4 & 24 & 7000 & 1100 & 3.47 & 1.80 & 36 & 28 & 7000 & 1100 & 5.19 & 1 \\
\hline 5 & 24 & 9000 & 500 & 5.88 & 3.62 & 37 & 28 & 9000 & 500 & 9.73 & 2 \\
\hline 6 & 24 & 9000 & 700 & 5.37 & 3.09 & 38 & 28 & 9000 & 700 & 8.24 & 2 \\
\hline 7 & 24 & 9000 & 900 & 5.10 & 2.74 & 39 & 28 & 9000 & 900 & 6.40 & 1 \\
\hline 8 & 24 & 9000 & 1100 & 4.42 & 2.40 & 40 & 28 & 9000 & 1100 & 5.84 & 1 \\
\hline 9 & 24 & 11000 & 500 & 7.29 & 3.87 & 41 & 28 & 11000 & 500 & 9.89 & 2 \\
\hline 10 & 24 & 11000 & 700 & 6.26 & 3.11 & 42 & 28 & 11000 & 700 & 9.09 & 2 \\
\hline 11 & 24 & 11000 & 900 & 5.28 & 2.89 & 43 & 28 & 11000 & 900 & 7.02 & 2 \\
\hline 12 & 24 & 11000 & 1100 & 4.93 & 2.62 & 44 & 28 & 11000 & 1100 & 6.10 & 2 \\
\hline 13 & 24 & 13000 & 500 & 7.74 & 4.06 & 45 & 28 & 13000 & 500 & 10.10 & 3 \\
\hline 14 & 24 & 13000 & 700 & 6.53 & 3.57 & 46 & 28 & 13000 & 700 & 9.39 & 2 \\
\hline 15 & 24 & 13000 & 900 & 5.53 & 3.07 & 47 & 28 & 13000 & 900 & 7.33 & 2 \\
\hline 16 & 24 & 13000 & 1100 & 5.17 & 2.74 & 48 & 28 & 13000 & 1100 & 6.48 & 2 \\
\hline 17 & 26 & 7000 & 500 & 6.94 & 2.56 & 49 & 30 & 7000 & 500 & 9.34 & 2 \\
\hline 18 & 26 & 7000 & 700 & 5.51 & 1.96 & 50 & 30 & 7000 & 700 & 7.22 & 1 \\
\hline 19 & 26 & 7000 & 900 & 4.91 & 1.70 & 51 & 30 & 7000 & 900 & 6.87 & 1 \\
\hline 20 & 26 & 7000 & 1100 & 4.41 & 1.43 & 52 & 30 & 7000 & 1100 & 5.50 & 1 \\
\hline 21 & 26 & 9000 & 500 & 7.92 & 2.67 & 53 & 30 & 9000 & 500 & 10.21 & 2 \\
\hline 22 & 26 & 9000 & 700 & 6.65 & 2.21 & 54 & 30 & 9000 & 700 & 8.75 & 1 \\
\hline 23 & 26 & 9000 & 900 & 5.88 & 2.06 & 55 & 30 & 9000 & 900 & 6.57 & 1 \\
\hline 24 & 26 & 9000 & 1100 & 5.17 & 1.89 & 56 & 30 & 9000 & 1100 & 6.16 & 1 \\
\hline 25 & 26 & 11000 & 500 & 8.87 & 3.36 & 57 & 30 & 11000 & 500 & 10.51 & 2 \\
\hline 26 & 26 & 11000 & 700 & 7.58 & 2.81 & 58 & 30 & 11000 & 700 & 9.57 & 2 \\
\hline 27 & 26 & 11000 & 900 & 6.64 & 2.46 & 59 & 30 & 11000 & 900 & 8.47 & 2 \\
\hline 28 & 26 & 11000 & 1100 & 5.56 & 2.21 & 60 & 30 & 11000 & 1100 & 6.35 & 1 \\
\hline 29 & 26 & 13000 & 500 & 9.02 & 3.98 & 61 & 30 & 13000 & 500 & 10.53 & 3 \\
\hline 30 & 26 & 13000 & 700 & 8.74 & 3.44 & 62 & 30 & 13000 & 700 & 9.68 & 2 \\
\hline 31 & 26 & 13000 & 900 & 6.98 & 3.03 & 63 & 30 & 13000 & 900 & 8.74 & 2 \\
\hline 32 & 26 & 13000 & 1100 & 6.02 & 2.51 & 64 & 30 & 13000 & 1100 & 7.03 & 2 \\
\hline
\end{tabular}

The data in Table 2 reveal the nonlinear relationship between the welding process parameters and the geometry parameters of weld bead. An artificial neural network which structure is shown in Fig. 8 are used to approximate the nonlinear relationship. There are three inputs and two outputs in the network, which contain a hidden layer.

The correlation coefficient of the test samples was 0.99615 and the mean square error was 0.0687 , indicating that the BP neural network had strong generalization ability and could effectively predict the width and height of weld bead. With the accurate prediction model, the prediction model can be coupled with the optimization algorithm, so as to realize the inverse welding parameters.

As shown in Fig. 10, the target width and height are set first. The error between target parameters and prediction parameters calculated by BP network is used as the fitness by genetic algorithm. The smaller the fitness, the easier the individual to retain in the iterative process. With the increase of the iterative number, the error becomes smaller and smaller, and finally the welding process parameters corresponding to the target parameters of weld bead can be obtained.

In fact, WAAM process is a fusion process of multiple weld beads. The smaller the weld spacing is, the better the surface flatness will be, but the higher the height will be. The larger the weld spacing is, the worse the surface flatness will be, and the lower the average height will be. Generally, when the weld spacing 
is about $1 / 2$ of the weld width, the surface flatness and the height are more appropriate. As shown in Fig. $11 \mathbf{b}$, the cross section could be not completely flat after the overlap of multiple welds, as long as the surface flatness reaches the allowable error.

\section{Automatic Waam System And Application 4.1 Automatic WAAM System}

WAAM system, shown in Fig.12, includes the welding actuator, hammer system and vacuum actuator. The maximum working stroke of the equipment is $4000 \mathrm{~mm} \times 1600 \mathrm{~mm} \times 600 \mathrm{~mm}$, and the maximum size of parts that can be manufactured is $4650 \mathrm{~mm} \times 1800 \mathrm{~mm} \times 800 \mathrm{~mm}$.

Both the hammering system and the welding system have three axes, so there are six independent axes in total. Welding and hammering alternately occur during additive manufacturing. The vacuum system can remove the welding slag so that the welding slag of the previous layer does not affect the welding of the next layer. The welding current in the digital automatic welder is automatically adjusted without external control, and the welding voltage and wire feeding speed is controlled by the external digital signal from robot system.

\subsection{Application of Automatic WAAM}

The repair process of hot forging die includes: removal of failure area, 3D scanning, extraction of target model, layer design, cleaning of die base, preheating of die base, transition layer welding, strengthening layer welding, post-welding heat treatment, machining and other steps. Firstly, carbon arc gouging was used to remove the cracks, holes and burning defects in the failure area of the die base, and then the metal oxides inside the die were cleaned with slag removal gun. Secondly, 3D scanning technology is used to get the STL model of the die cavity after carbon arc gouging, and then the scanned model is processed to get the NURBS surface. Then the target model that needs to be produced can be obtained through the difference Boolean operation of the standard model and scanned model. Thirdly, the temperature distribution and stress distribution of the hot forging die in service are analyzed in CAE software. Depending on the simulation results and experience, the target model was sliced into the transition layer and the reinforcement layer by using CAD software. Fourthly, the self-developed path planning system that converts the path data into G-code is used to design the welding path of the transition layer using vertical additive and the reinforcement layer using normal additive algorithm respectively. Fifth, forging die is preheated for 24 hours at the temperature of 500 . If the preheating temperature is too low, the die will crack after welding; if the temperature is too high, the grain of the base will change. Sixth, the vertical additive algorithm is first used to manufacture the transition layer, and then the reinforcement layer is manufactured by using the normal additive algorithm. In the welding process, $80 \% \mathrm{Co} 2+20 \% \mathrm{Ar}$ shielding gas is used for the Fe-based alloy, and $98 \% \mathrm{Arc}+2 \% \mathrm{Co} 2$ shielding gas is used for the Co-based alloy. Seventh, after the completion of additive manufacturing, put the mold in a heating furnace and keep it at 400 for 24 hours to fully release the welding residual stress, then cool it with the furnace. Eighth, after the tempering is finished, mechanical processing is performed to remove the excess material on the additive manufacturing surface.

To test the remanufacturing method discussed in this paper, an ultra-large aviation hot forging die was selected as trail production. The size of the ultra-large aviation hot forging die is $4020 \mathrm{~mm} * 1110 \mathrm{~mm} * 767 \mathrm{~mm}$, and its weight is about $25 \mathrm{~T}$. Normally only WAAM technology can remanufacture such a large mold.

Figure 13 shows the extraction process of a target model for an ultra-large aviation forging die, in which the scanning point cloud is processed to obtain the scanning model, and then the scanning model is subtracted from the standard model to obtain the target model. The transition layer and the strengthening layer has been designed in figure 15, in which the thickness of the reinforcement layer is designed to be $5 \mathrm{~mm}$. The additive manufacture of the transition layer and the reinforcement layer uses Fe-based alloy and Co-based alloy respectively.

The diameter of the solid core welding wire is $1.6 \mathrm{~mm}$. The designed weld width and height are about $8 \mathrm{~mm}$ and $4 \mathrm{~mm}$ respectively. The approximate process parameters were obtained through the reverse solving system of the welding process parameters, and verified by welding test that the process parameters were: welding voltage: $28 \mathrm{~V}$, wire feeding speed $: 11000 \mathrm{~mm} / \mathrm{min}$, welding speed: $800 \mathrm{~mm} / \mathrm{min}$.

As shown in Fig. 15a, in the WAAM process, the surface of the die is insulated with thermal insulation materials, and the bottom of the die is heated by a heating flat car, so as to ensure that the temperature of the die in the welding process is maintained at $450-500^{\circ} \mathrm{C}$. The welding gun is placed vertically and can be moved along the $\mathrm{XYZ}$ axis to ensure that it moves in line with the preset welding path.

As shown in Fig. 15b, there are many protruding on the surface of the die after additive remanufacturing. This is because there is a step error in the height direction when multiple welds are joined together to form an inclined plane. Generally, the smaller the weld bead is, the smaller the step error is. The step error can be reduced by reducing weld width and height, but the efficiency of additive remanufacturing will be reduced. In order to ensure the efficiency, the machining allowance can be increased appropriately to ensure that the step error region can be removed in the machining process. As shown in Fig. $15 \mathrm{C}$, by increasing the machining allowance, a smooth and integrated cavity can be obtained although there is a step error.

\subsection{Application Analysis}

As shown in Fig.16, the mechanical allowance can be controlled within about 3-5mm by using automatic WAAM technology. Since the welding shape cannot be accurately controlled by manual welding, the machining allowance is usually greater than $10 \mathrm{~mm}$. Compared with manual repair method, automatic WAAM technology can save at least $50 \%$ of the material. At the same time, the machining volume is reduced, so the machining time can be reduced by approximately $50 \%$. 
The automatic WAAM method can reduce the manufacturing cost of the die by more than $50 \%$. There are three reasons for the increase of die life. The first reason is that the welding process of robot is relatively stable compared with manual welding, so there are fewer welding defects. The second reason is that layering design and layering additive manufacturing can take advantage of the high-temperature properties of Co-based alloy and the low-temperature strength of Fe-based alloy.

The third reason is that robot hammering can greatly eliminate the welding residual stress, so that the residual tensile stress on the die surface is forced to change to the residual compressive stress.

As shown in Fig.17, the forgings are made of titanium alloy and heated to 960 . The under-pressure of the forgings was analyzed by 3D scanner, and the analysis results showed that the forgings were full in shape.

\section{Conclusion}

(1) Vertical additive manufacturing and normal additive manufacturing algorithms are proposed and the corresponding additive manufacturing systems are developed, which are successfully applied in volume additive manufacturing and surfacing additive manufacturing processes. The wear resistance of Febased alloy, Co-based alloy and Ni-based alloy at high and low temperatures was studied. The results showed that the wear resistance of Fe-based alloy, Cobased alloy and Ni-based alloy at low temperature was from high to low, and that of Co-based alloy, Ni-based alloy and Fe-based alloy at high temperature was from high to low.

(2) According to the temperature and stress difference of the die in service, the layering design strategy and material selection principle for hot forging die are put forward in which the hot forging die is divided into three layers: base layer, transition layer and strengthening layer. Co-based material was used in the high temperature area (strengthening layer) of the die, ordinary die steel can was used in the low temperature area(base layer), and Fe-based material should be used in the medium temperature area(transition layer).

(3) The remanufacturing of a typical aviation super-large hot forging die proves that the algorithm and system proposed in this paper can effectively complete the remanufacturing repair of this kind of forging die with gradient additive. On the one hand, from the service results of the repaired forging dies, the service life of the hot forging dies repaired with gradient function additive is significantly increased compared with the manual repair hot forging dies. On the other hand, the automatic gradient remanufacturing can save the material compared with the manual remanufacturing. In addition, due to its harsh welding environment, such as high temperature, arc light, exhaust gas, which will lead to manual repair difficulties, automatic gradient additive can significantly improve the repair efficiency.

\section{Declarations}

Ethical approval: Not applicable

Consent to Participate: Not applicable

Consent to Publish: All the authors gave their consent for the manuscript to be published.

Authors Contributions: Xiaoying Hong put forward the relevant algorithm and ideas, and wrote the article. Guiqian Xiao wrote the software and developed the hardware and carried out experiments. Yancheng Zhang did the welding process parameter experiment. Jie Zhou guided and reviewed the whole process.

Funding: This research is supported by National Key Research and Development Program of China (No.2018YFB1106504).

Competing Interests: No conflict of interest exists in the submission of this manuscript, and manuscript is approved by all authors for publication. I would like to declare on behalf of my co-authors that the work was original research that has not been published previously.

Availability of data and materials: All data generated or analyzed during this study are included in this published article.

\section{Reference}

1. b Xiong. Research on Optimization of forging Process for Aero-engine Casing and Die manufacturing by Gradient Surfacing Welding[D]. Chongqing University, 2018.

2. s Zhang, J Zhou, Y.p Tao, et al. The microstructure and properties change of dies manufactured by bimetal-gradient-layer surfacing technology[J]. The International Journal of Advanced Manufacturing Technology, 2015, 80: 1804-1807.

3. Shen L, Zhou J , Ma X , et al. Microstructure and mechanical properties of hot forging die manufactured by bimetal-layer surfacing technology[J]. Journal of Materials Processing Technology, 2017, 239:147-159.

4. Morrow W R, Qi H, Kim I, et al. Environmental aspects of laser-based and conventional tool and die manufacturing[J]. Journal of Cleaner Production, 2007, 15(10):932-943.

5. Huang R, Riddle M , Graziano D , et al. Energy and emissions saving potential of additive manufacturing: thecase of lightweight aircraft components[J]. Journal of Cleaner Production, 2016, 135(nov.1):1559-1570. Watson J K, Taminger K M B . A decision-support model for selecting additive manufacturing versus subtractive manufacturing based on energy consumption[J]. Journal of Cleaner Production, 2015, 176(MAR.1):1316-1322.

6. Frazier, William E . Metal Additive Manufacturing: A Review[J]. Journal of Materials Engineering \& Performance, 2014, $23(6): 1917-1928$. 
7. Wong K V , Hernandez A . A Review of Additive Manufacturing[J]. Isrn Mechanical Engineering, 2012, 2012:30-38.

8. Ding D , Pan Z , Cuiuri D , et al. A tool-path generation strategy for wire and arc additive manufacturing[J]. International Journal of Advanced Manufacturing Technology, 2014, 73(1-4):173-183.

9. Pan, Zengxi, Ding, et al. A practical path planning methodology for wire and arc additive manufacturing of thin-walled structures[J]. Robotics \& Computer Integrated Manufacturing An International Journal of Manufacturing \& Product \& Process Development, 2015.

10. Ding D , Pan Z , Cuiuri D, et al. Bead modelling and implementation of adaptive MAT path in wire and arc additive manufacturing[J]. Robotics and Computer-Integrated Manufacturing, 2016, 39(Jun.):32-42.

11. h Ding, Z.x Pan, D. Cuiuri, et al. Adaptive path planning for wire-feed additive manufacturing using medial axis transformation[J]. Journal of Cleaner Production, 2016, 133: 942-952.

12. Jin Y , Du J , Ma Z , et al. An optimization approach for path planning of high-quality and uniform additive manufacturing[J]. The International Journal of Advanced Manufacturing Technology, 2017.

13. Nguyen L , Buhl J , Bambach M . Decomposition algorithm for tool path planning for wire-arc additive manufacturing[J]. 2018.

14. Falk B , Engel U, Geiger M . Estimation of tool life in bulk metal forming based on different failure concepts[J]. Journal of Materials Processing Technology, 1998, s 80-81(98):602-607.

15. Hua-Chang W, Chun Y, Hua-Jun W , et al. Temperature Field of the Hot Forging Die Under the Continuous Working State[J]. Journal of Wuhan University of Technology, 2008.

16. Lu S , Zhou J , Zhang J . Optimization of welding thickness on casting-steel surface for production of forging die[J]. International Journal of Advanced Manufacturing Technology, 2015, 76(5-8):1411-1419.

17. R, George, A, et al. Hot forming of boron steels using heated and cooled tooling for tailored propertie[J]. Journal of Materials Processing Technology, 2012.

18. Medea, F, Hamasaiid, et al. Tribological behavior of high thermal conductivity steels for hot stamping tools[J]. Tribology International, 2016.

19. Kemin Zhang, Jie Zhou, Mengmeng Zhang, et al. A comparison study on wear characteristics of Ni-based, Co-based and Fe-based alloys for heated hot stamping tools manufactured by surfacing technology[J]. The International Journal of Advanced Manufacturing Technology, 2020, 106: 3659-3668.

20. Rynio C , Hattendorf H , J. Klöwer, et al. The evolution of tribolayers during high temperature sliding wear[J]. Wear, 2014.

21. Hejwowski T. Sliding wear resistance of Fe, Ni and Co-based alloys for plasma deposition[J]. Vacuum, 2006, 80(11):1326-1330.

\section{Figures}
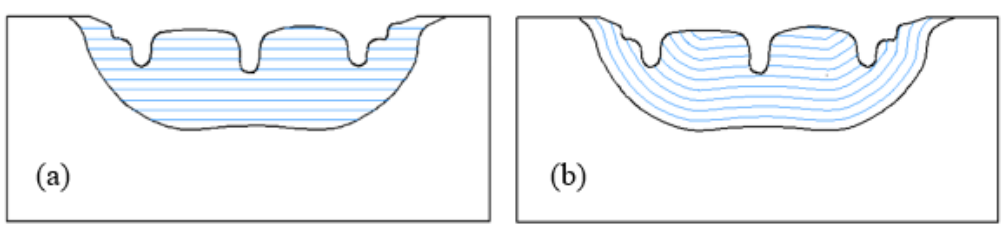

Figure 1

Two strategies of additive manufacturing process. (a) VAM;(b) NAM.
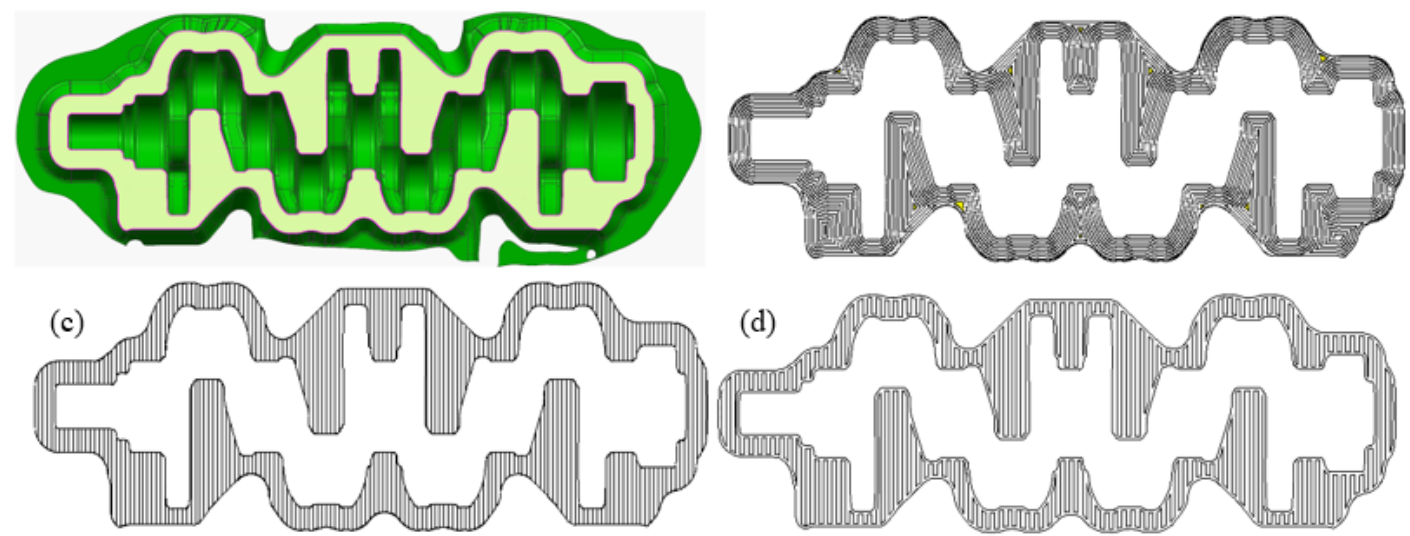

\section{Figure 2}

Different filling algorithms for crankshaft die for VAM. (a) target model and a vertical slicing section; (b) offset filling; (c) linear filling; (d) hybrid filling. 
(a)

(c)

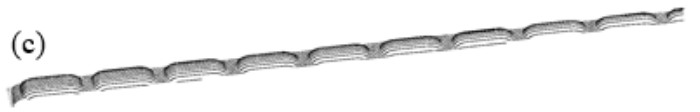

(b)

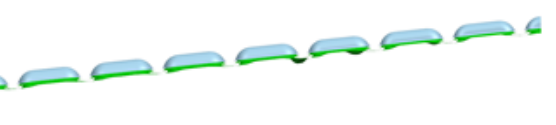

\section{Figure 3}

Path planning algorithm for normal slicing (a) additive target model; (b) normal slicing model; (c) additive path in length direction; (d) additive path in height direction;

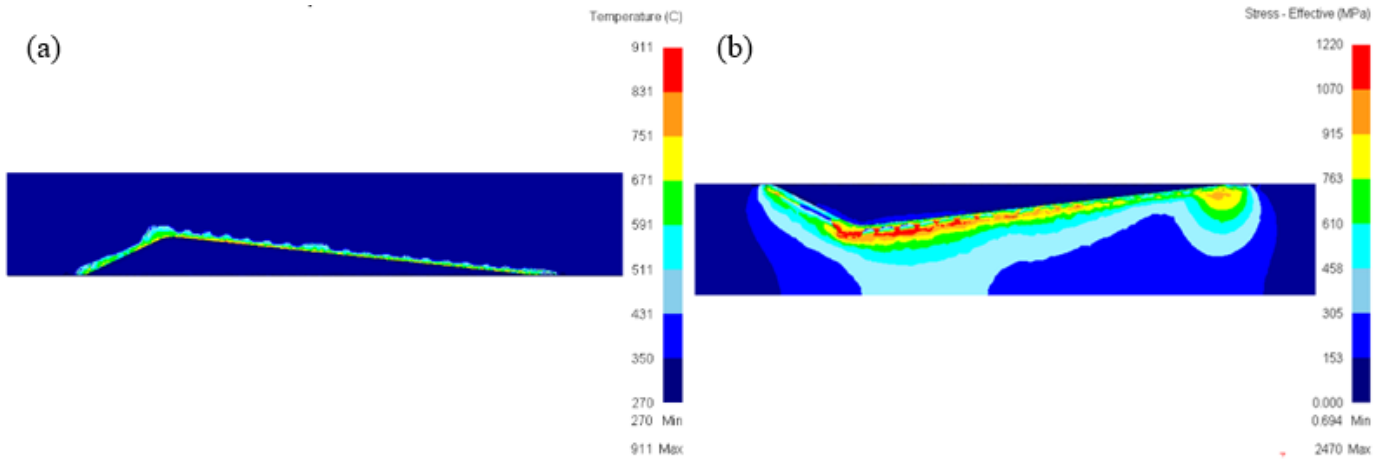

\section{Figure 4}

Temperature and effective stress distribution of a typical ultra-large hot forging die in service. (a) Temperature distribution; (b) effective stress

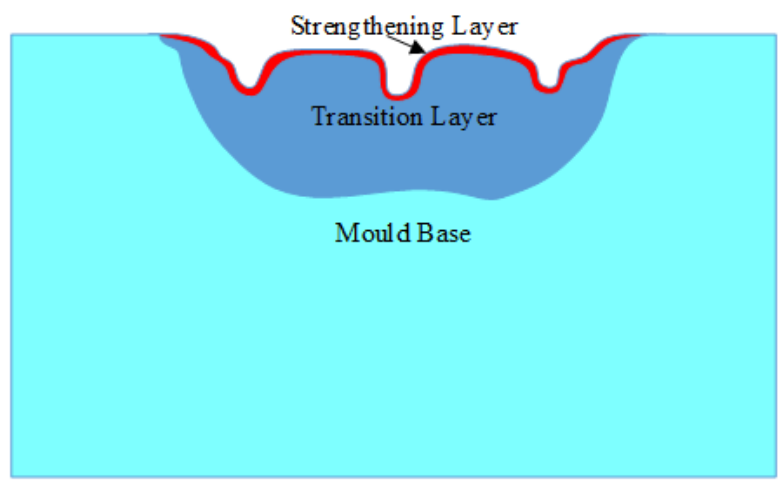

\section{Figure 5}

Three-layer design of a hot forging die

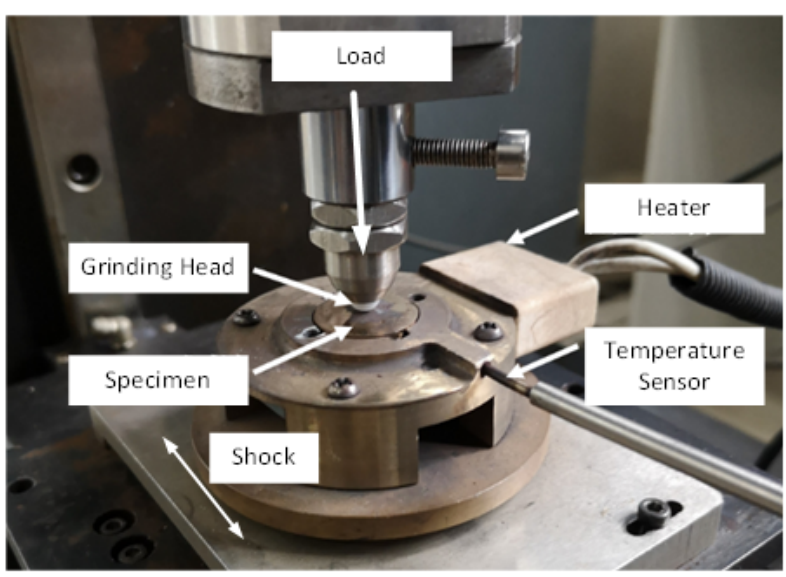

\section{Figure 6}

Wear test at elevated temperature 

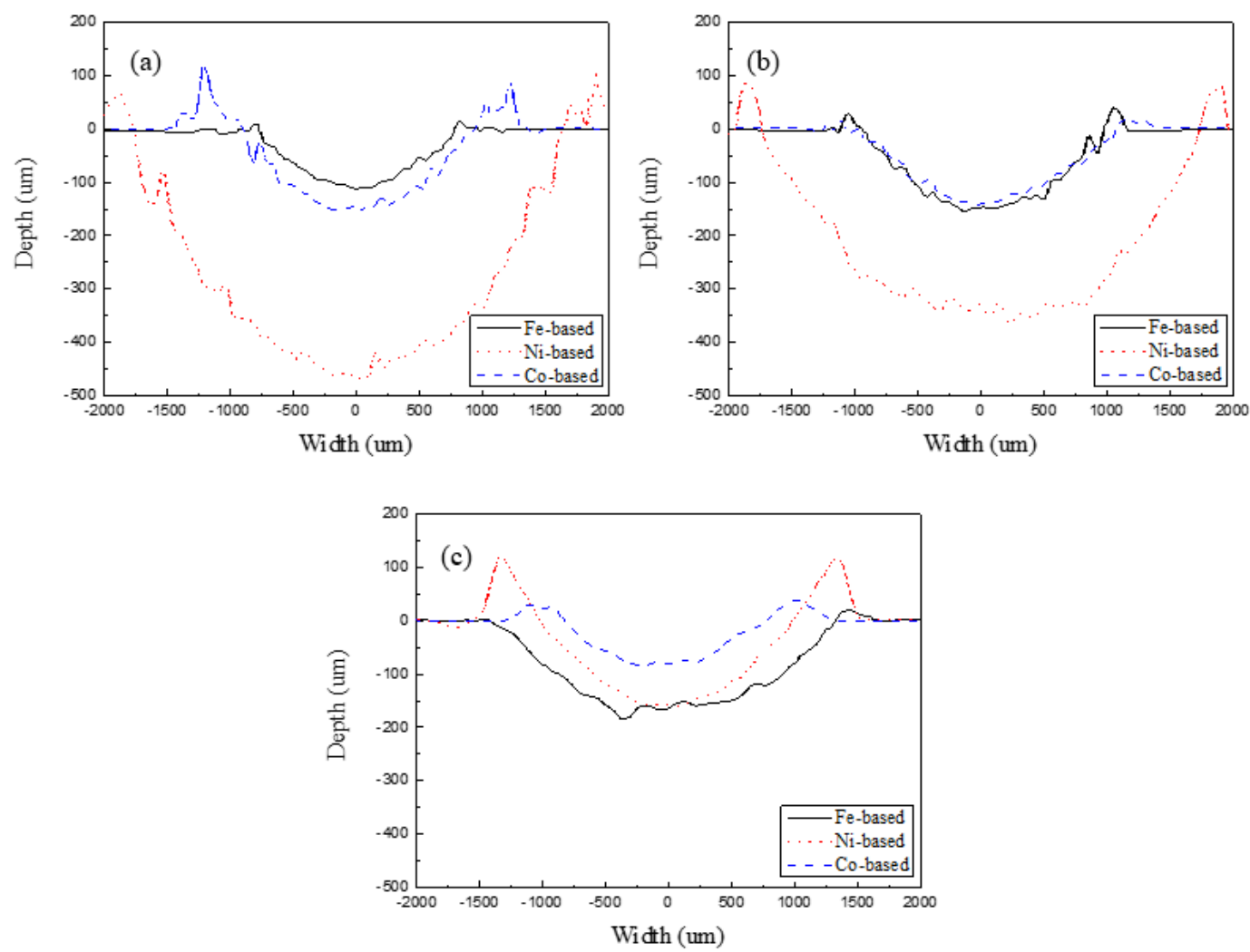

Figure 7

Worn track width and depth comparison for Fe-based, Ni-based, Co-based alloy at low and high temperature under (a) $25^{\circ} \mathrm{C}$; (b) $300^{\circ} \mathrm{C}$; (c) $800^{\circ} \mathrm{C}$

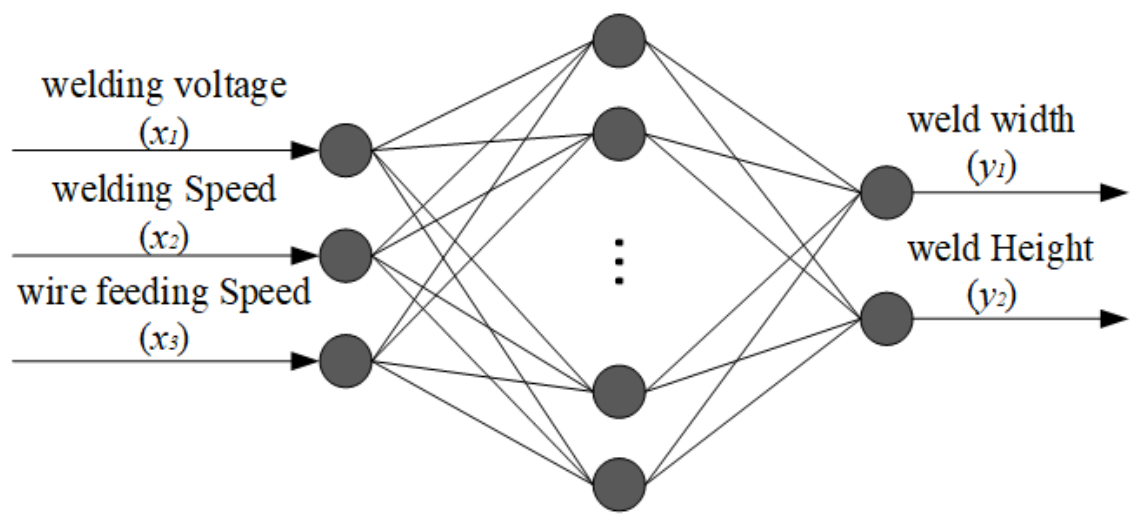

Figure 8

Structure of artificial neural network
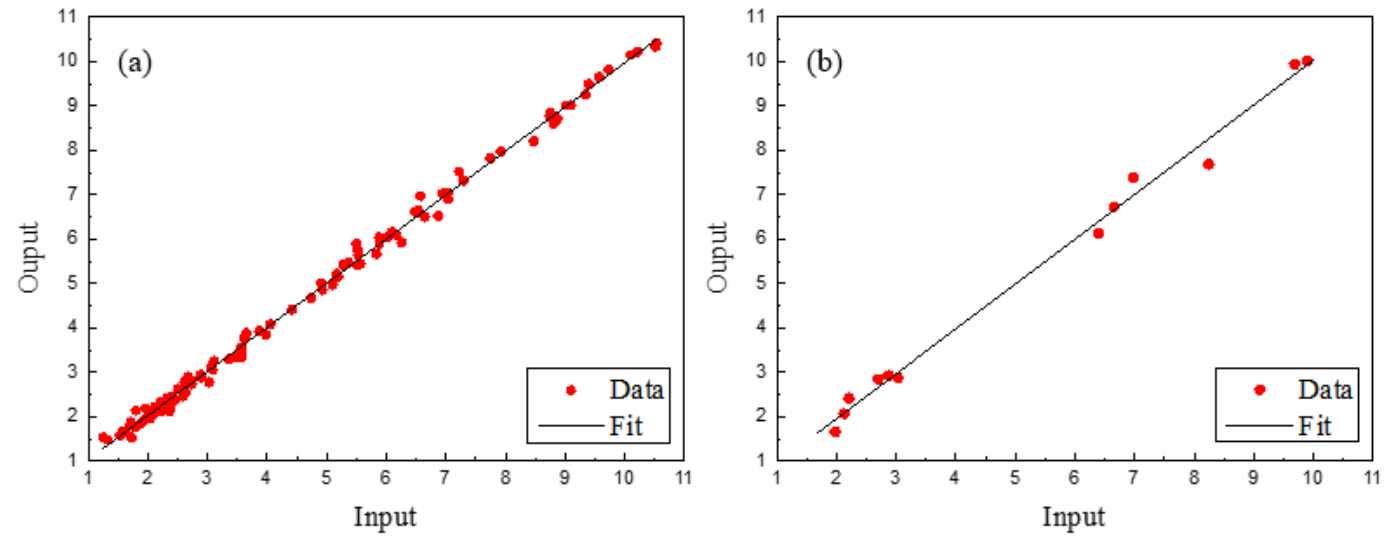

Page 10/13 
Figure 9

The correlation relationships between the experimental and BP predicted values (a) training samples $(R=0.9985, M S E=0.0205)$; $(b)$ training samples(R=0.99615, MSE=0.0687)

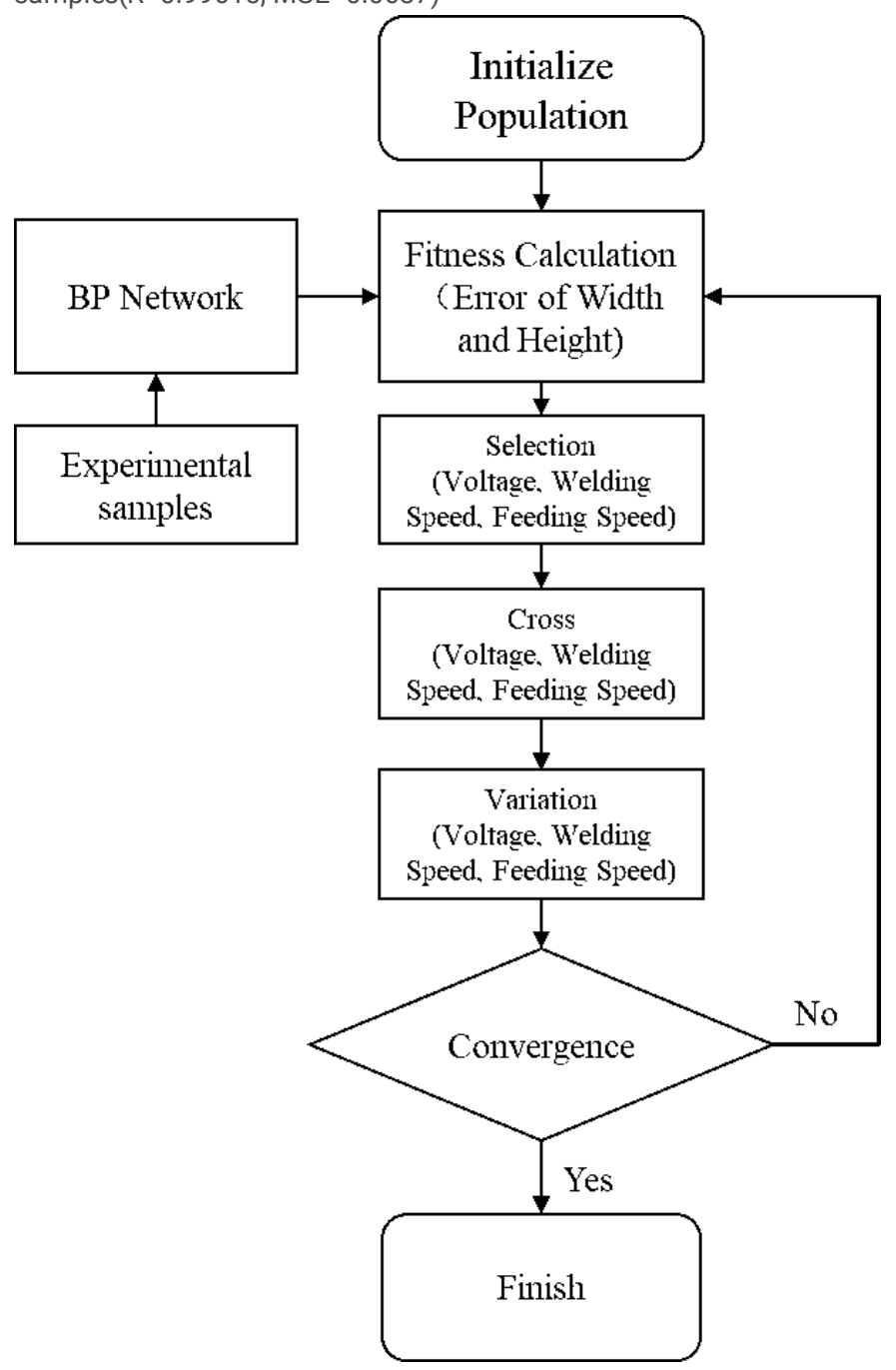

Figure 10

Reverse algorithm of solving process parameters

(a)

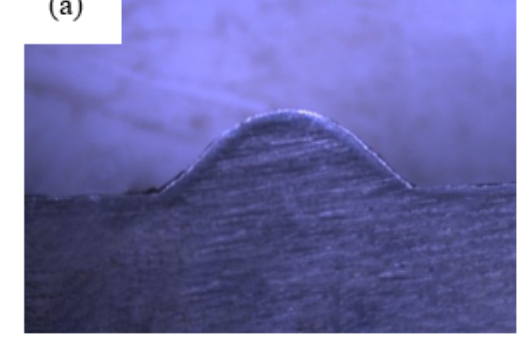

Figure 11 (b)

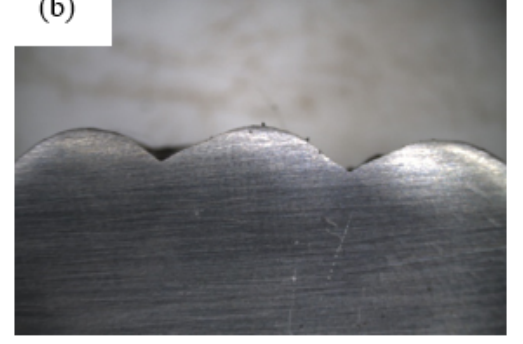

Weld shape. a Single weld. b Three pass weld 


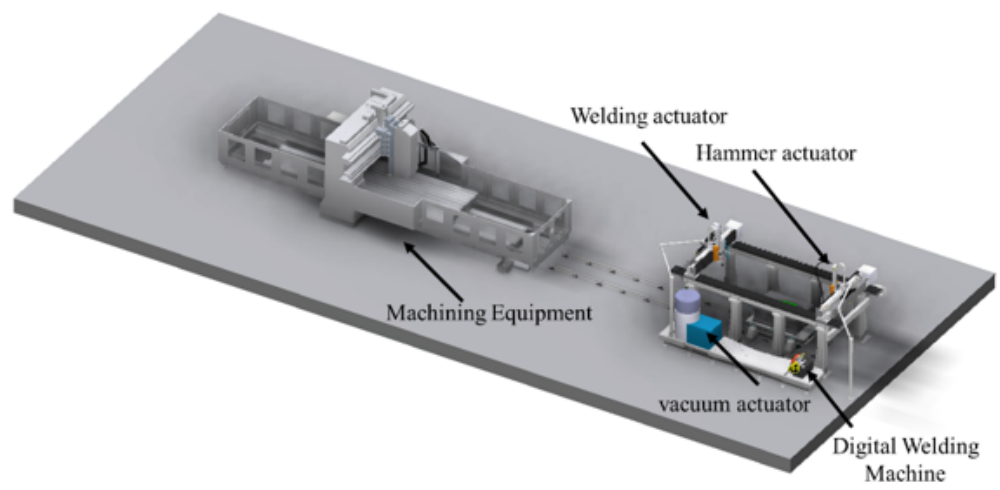

\section{Figure 12}

Automatic Wire Arc Additive Manufacturing System

(a)
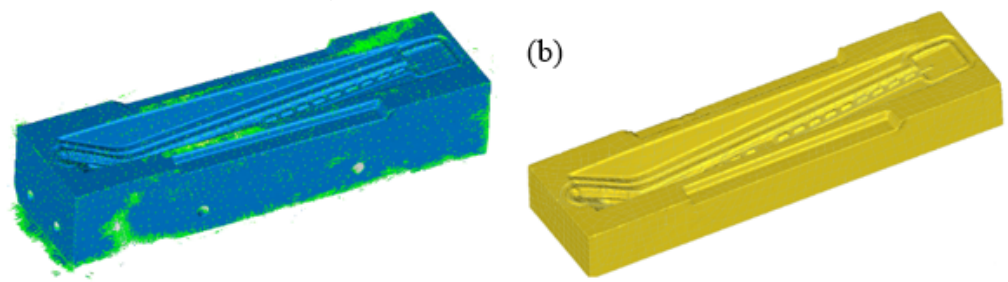

(c)
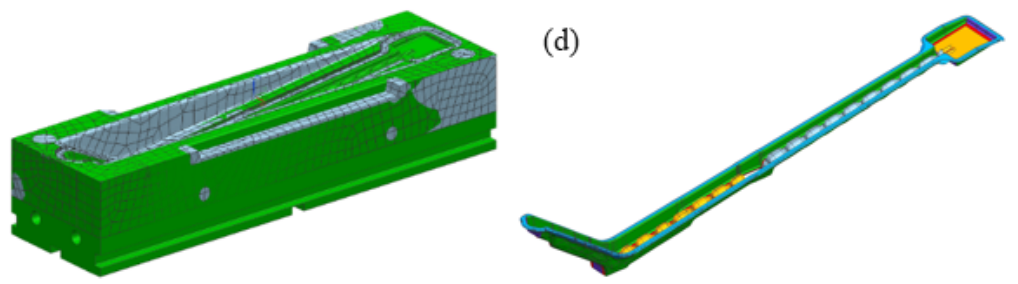

\section{Figure 13}

Target model extraction process of an aviation hot forging die (a) Scanning point cloud; (b) Packaged and repaired model; (c) Alignment of scan model and standard model; (d) Target model of additive manufacturing

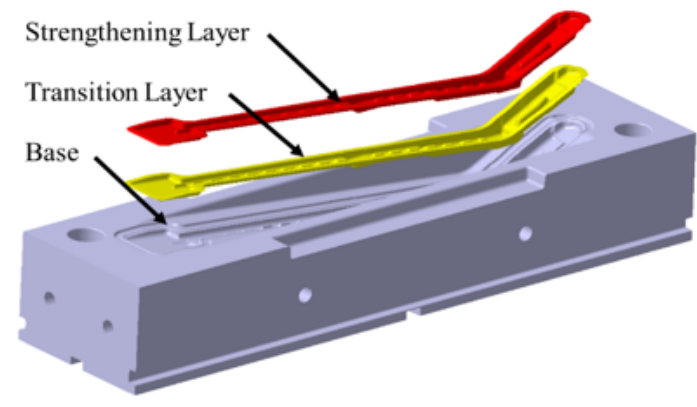

\section{Figure 14}

Layer design of transition layer and strengthening layer 

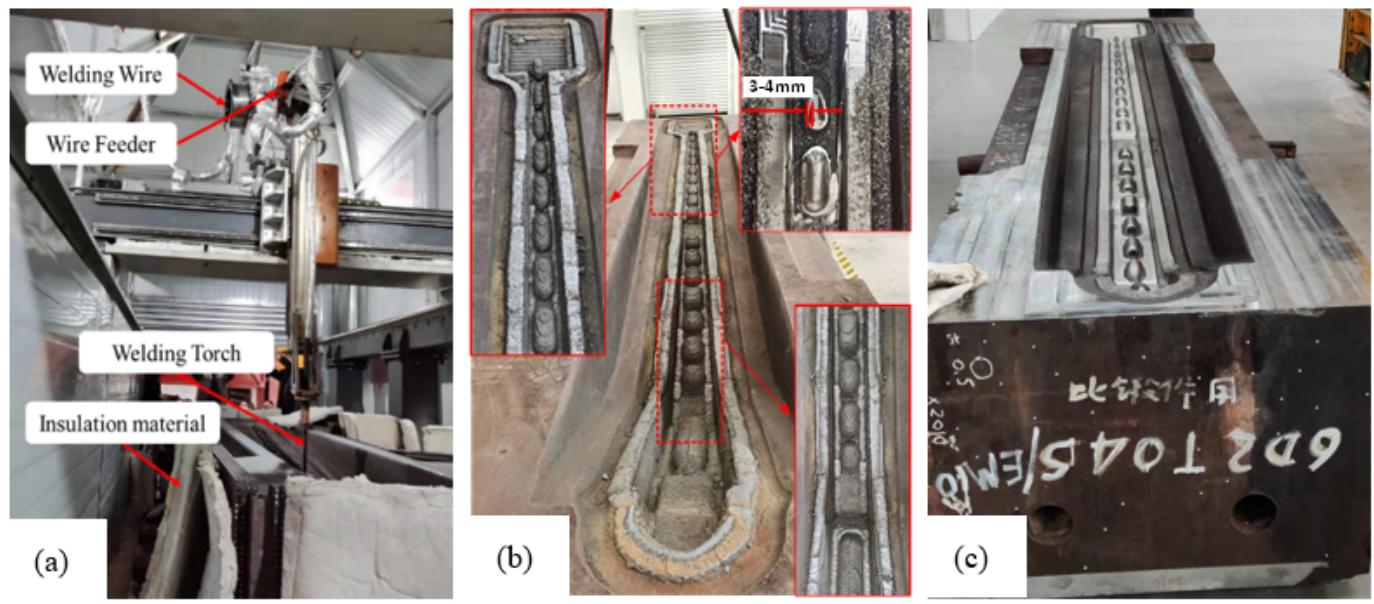

Figure 15

Repaired ultra-large hot forging die (a) Repairing site; (b) Repaired hot forging die;(c) Hot forging die after machining

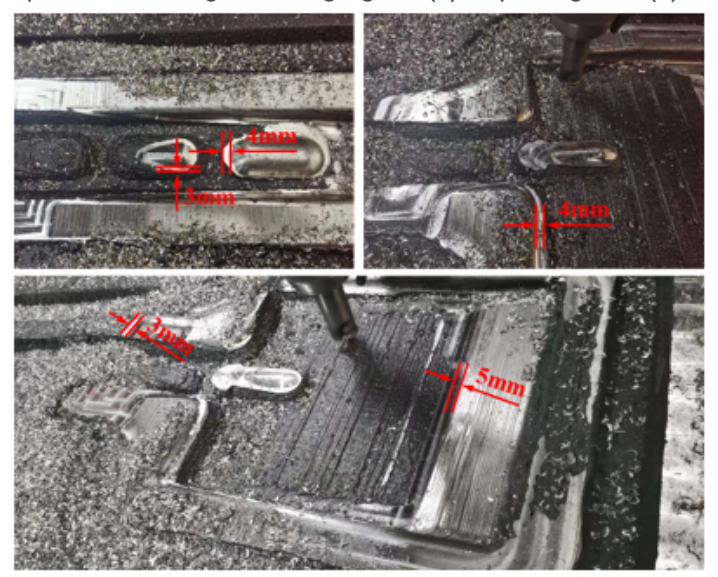

\section{Figure 16}

Machining allowance

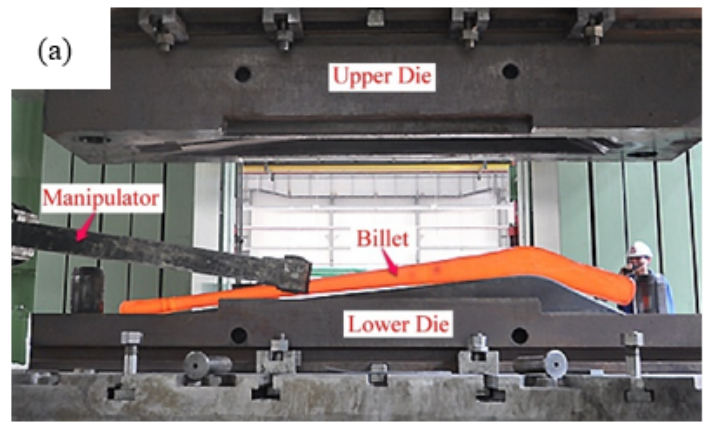

(b)

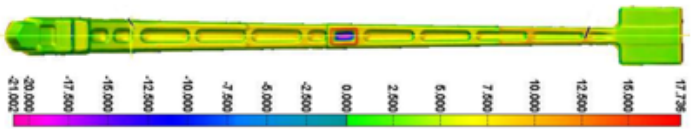

Figure 17

Service scene and forging measurement (a) Service scene; (b) Under-pressure analysis 